\title{
Investigation of the Dynamic Properties of Seawater-Resistant Rubber
}

\author{
Evgeniy N. Egorov ${ }^{a}$, \\ Nikolay F. Ushmarin ${ }^{b}$, Sergei I. Sandalov ${ }^{b}$, \\ Nikolay I. Kol'tsova and Vasiliy D. Voronchikhin ${ }^{\mathrm{c} *}$ \\ ${ }^{a}$ Chuvash State University after named I.N. Ulyanov \\ Cheboksary, Russian Federation \\ ${ }^{b}$ Cheboksary Production Association named after V.I. Chapaev \\ Cheboksary, Russian Federation \\ ${ }^{c}$ Reshetnev Siberian State University of Science and Technology \\ Krasnoyarsk, Russian Federation
}

Received 26.11.2020, received in revised form 17.01.2021, accepted 10.03.2021

\begin{abstract}
The influence of rubbers, trans-polynorbornene, polyisobutylene P-200 and sevilene on vulcanization characteristics, physical-mechanical and dynamic properties of rubber used for the manufacture of products in contact with sea water has been investigated. It has been established that the developed rubber with a sulfur vulcanizing system based on rubbers SKMS-30ARK, SKN-4065 and BK-1675 with additives of trans-polynorbornene and sevilene 11808-340 has improved physical and mechanical characteristics, resistance to sea water and increased dynamic properties.
\end{abstract}

Keywords: rubber, rubbers, trans-polynorbornene, polyisobutylene, sevilene, physicomechanical and dynamic properties, durability, sea water, tangent of mechanical loss angle, elastic modulus.

Citation: Egorov E.N., Ushmarin N.F., Sandalov S.I., Kol'tsov N.I., Voronchikhin V.D. Investigation of the dynamic properties of seawater-resistant rubber, J. Sib. Fed. Univ. Chem., 2021, 14(1), 38-44. DOI: 10.17516/1998-2836-0214

(C) Siberian Federal University. All rights reserved

This work is licensed under a Creative Commons Attribution-NonCommercial 4.0 International License (CC BY-NC 4.0).

* Corresponding author E-mail address: vvd-77@mail.ru 


\title{
Исследование динамических свойств стойкой к морской воде резины
}

\author{
Е.Н. Егоров ${ }^{\text {a }}$ Н. Ф. Ушмарин ${ }^{\sigma}$, \\ С. И. Сандалов ${ }^{\sigma}$, Н.И. Кольцов ${ }^{a}$, В. Д. Ворончихинв \\ ачувашский государственный университет им. И. Н. Ульянова \\ Российская Федерачия, Чебоксары \\ ${ }^{6}$ Чебоксарское производственное объединение им. В. И. Чапаева \\ Российская Федерачия, Чебоксары \\ ${ }^{8}$ Сибирский государственный университет науки \\ и технологий им. ак. М. Ф. Решетнева \\ Российская Федераиия, Красноярск
}

\begin{abstract}
Аннотация. Исследовано влияние каучуков, транс-полинорборнена, полиизобутилена П-200 и сэвилена на вулканизационные характеристики, физико-механические и динамические свойства резины, используемой для изготовления изделий, контактирующих с морской водой. Установлено, что разработанная резина с серной вулканизующей системой на основе каучуков СКМС-30АРК, СКН-4065 и БК-1675 с добавками транс-полинорборнена и сэвилена 11808-340 обладает улучшенными физико-механическими показателями, стойкостью к воздействию морской воды и повышенными динамическими свойствами.
\end{abstract}

Ключевые слова: резина, каучуки, транс-полинорборнен, полиизобутилен, сэвилен, физикомеханические и динамические свойства, стойкость, морская вода, тангенс угла механических потерь, модуль упругости.

Цитирование: Егоров, Е.Н. Исследование динамических свойств стойкой к морской воде резины / Е. Н. Егоров, Н. Ф. Ушмарин, С. И. Сандалов, Н. И. Кольцов В. Д. Ворончихин // Журн. Сиб. федер. ун-та. Химия, 2021, 14(1). С. 3844. DOI: $10.17516 / 1998-2836-0214$

В настоящее время для изготовления резинотехнических изделий для нефтеналивных танкеров, газонефтедобывающих платформ, эксплуатируемых в условиях воздействия морской воды, применяются резиновые смеси на основе каучуков общего и специального назначения. Однако в связи с повышением требований к изделиям, работающим длительное время в морской воде, актуальна разработка резин с улучшенными физико-механическими и динамическими свойствами. Данные материалы выполняют роль виброизоляторов и должны иметь высокие значения тангенса угла механических потерь ( $\operatorname{tg} \delta>0,3)$, характеризующего величину рассеивания энергии вибрации. Основой таких резин являются каучуки общего и специального назначения. Для усиления их свойств требуется использовать специальные ингредиенты. Один из таких ингредиентов - транс-полинорборнен (ТПНБ), позволяющий повысить динамические свойства полимеров и композиционных материалов [1-9], а также резиновых покрытий на основе комбинации бутадиен-нитрильного, изопренового [10] и бутадиен-метилстирольного каучука [11]. Улучшенными динамическими свойствами обладают резины на основе бутилкаучука [12], 
полиизобутилена [13] и сэвилена [14]. В связи с этим в данной работе проведен подбор каучуков и изучено влияние ТПНБ, полиизобутилена и сэвилена для резины, изделия из которой контактируют с морской водой, с целью повышения динамических характеристик с сохранением ее физико-механических свойств.

\section{Экспериментальная часть}

Исследуемая резиновая смесь была аналогом резиновой смеси, разработанной в [11]. Основой резиновой смеси служил бутадиен-метилстирольный каучук СКМС-30АРК, вулканизующим агентом являлась сера, ускорителем вулканизации - 2,2'-дибензтиазолдисульфид, активаторами вулканизации - белила цинковые, стеариновая кислота, противостарителями ацетонанил $\mathrm{H}, \mathrm{N}$-изопропил-N'-фенил-nара-фенилендиамин, наполнителями - технический углерод марки П 324, тонкомолотый шунгитовый порошок, мягчителем - масло индустриальное И-12А. Для варьирования физико-механических и динамических свойств резины в разных вариантах резиновой смеси вводились каучуки общего (СКИ-3) и специального (СКН-4065, БК-1675) назначения, ТПНБ, полиизобутилен высокомолекулярный П-200 и сэвилен 11808-340. ТПНБ использовали в виде модифицирующей добавки (МД), которую готовили путем смешения ТПНБ с маслом индустриальным И-12А при соотношении 1,0:1,5. Варианты резиновой смеси изготавливали на лабораторных вальцах ЛБ 320 160/160 при температуре $70-80{ }^{\circ} \mathrm{C}$ в течение 20 мин. Вулканизационные характеристики резиновой смеси исследовали на реомеTpe MDR3000 Basic фирмы «Mon Tech» при $150{ }^{\circ} \mathrm{C}$ в течение 30 мин в соответствии с ГОСТ 12535-84. Резиновую смесь вулканизовали при температуре $150{ }^{\circ} \mathrm{C}$ в течение 20 мин в вулканизационном прессе типа P-V-100-3RT-2-PCD. Для полученных вулканизатов определяли: упруго-прочностные свойства (ГОСТ 270-75); твердость (ГОСТ 263-75); сопротивление раздиру (ГОСТ 262-79); изменение массы вулканизатов в морской воде (8\%-ный раствор морской соли в воде) при температуре $23{ }^{\circ} \mathrm{C}$ в течение 30 сут. (ГОСТ 9.030-74). Динамические свойства (тангенс угла механических потерь и модуль упругости) вулканизатов исследовали на динамическом механическом анализаторе Metravib VHF 104 при частоте 1000 Гц и деформации 0,01\% (ГОСТ 23326-78).

\section{Результаты и их обсуждение}

Исследования проводили для пяти вариантов резиновой смеси. Первый (базовый) вариант резиновой смеси готовили на основе каучука СКМС-30АРКс применением масла индустриального И-12А. Второй вариант смеси содержал 40,0 мас. ч. МД, которая включала 16,0 мас. ч. ТПНБ и 24,0 мас. ч. И-12А, что соответствовало его содержанию в первом варианте. Первый и второй варианты содержали вулканизующую группу, которая включала серу и 2,2'-дибензтиазолдисульфид. В третий, четвертый и пятый варианты резиновой смеси вводилась МД в количестве 50,0 мас. ч. (20,0 мас. ч. ТПНБ и 30,0 мас. ч. И-12А). Причем в третьем и четвертом вариантах производилась частичная замена СКМС-30АРК на бутадиен-нитрильный СКН-4065 и изопреновый СКИ-3 каучуки соответственно. В этих вариантах в качестве вулканизующей системы использовали серу, 2,2'-дибензтиазолдисульфид и N-циклогексил-2-бензотиазолсульфенамид. В пятом варианте резиновой смеси СКМС-30АРК частично заменялся на СКН-4065 и бутилкаучук БК-1675. При этом в вулканизующую систему входили сера, 2,2'-дибензтиазолдисульфид 
Таблица. Варианты и свойства резиновой смеси и вулканизатов

Table. Variants and properties of rubber mixture and vulcanizates

\begin{tabular}{|c|c|c|c|c|c|}
\hline \multirow{2}{*}{ Ингредиент, показатель } & \multicolumn{5}{|c|}{ Варианты резиновой смеси } \\
\hline & 1 & 2 & 3 & 4 & 5 \\
\hline СКМС-30АРК, мас. ч. & 100,0 & 100,0 & 40,0 & 40,0 & 35,0 \\
\hline СКН-4065, мас. ч. & - & - & 30,0 & 30,0 & 45,0 \\
\hline СКИ-3, мас. ч. & - & - & 30,0 & 30,0 & - \\
\hline БК-1675, мас. ч. & - & - & - & - & 20,0 \\
\hline Полиизобутилен П-200, мас. ч. & - & - & - & 5,0 & - \\
\hline Сэвилен 11808-340, мас. ч. & - & - & - & - & 5,0 \\
\hline МД/ТПНБ, мас. ч. & - & $40,0 / 16,0$ & $50,0 / 20,0$ & $50,0 / 20,0$ & $50,0 / 20,0$ \\
\hline Масло индустриальное И-12А, мас. ч. & 24,0 & - & - & - & - \\
\hline Сера, мас. ч. & 2,5 & 2,5 & 2,5 & 2,5 & 2,5 \\
\hline 2,2'-Дибензтиазолдисульфид, мас. ч. & 1,0 & 1,0 & 1,2 & 1,2 & 1,5 \\
\hline N-Циклогексил-2-бензотиазолсульфенамид, мас. ч. & - & - & 0,8 & 1,0 & - \\
\hline Гуанид Ф, мас. ч. & - & - & - & - & 0,5 \\
\hline \multicolumn{6}{|c|}{ Вулканизационные характеристики резиновой смеси при $150^{\circ} \mathrm{C}$} \\
\hline$M_{\mathrm{H}}, д \mathrm{H} \cdot \mathrm{M}$ & 16,19 & 12,38 & 13,69 & 15,07 & 17,86 \\
\hline$M_{\mathrm{L}}, д \mathrm{H} \cdot \mathrm{M}$ & 2,07 & 1,86 & 2,23 & 2,45 & 2,52 \\
\hline$t_{\mathrm{s}}$, мин & 3,02 & 3,61 & 4,12 & 4,21 & 4,57 \\
\hline$t_{90}$, мин & 10,61 & 11,92 & 12,65 & 14,09 & 14,48 \\
\hline \multicolumn{6}{|c|}{ Физико-механические свойства вулканизатов (режим вулканизации 150 $\mathrm{C} \times 20$ мин) } \\
\hline$f_{100}$, МПа & 5,1 & 2,8 & 3,1 & 3,8 & 4,0 \\
\hline$f_{\mathrm{p}}, \mathrm{M \Pi а}$ & 14,5 & 11,0 & 11,7 & 12,8 & 13,4 \\
\hline$\varepsilon_{\mathrm{p}}, \%$ & 350 & 360 & 330 & 350 & 360 \\
\hline H, ед. Шор А & 59 & 56 & 58 & 62 & 67 \\
\hline$B, \kappa \mathrm{H}^{\prime} \mathrm{M}^{-1}$ & 41 & 32 & 34 & 35 & 38 \\
\hline \multicolumn{6}{|c|}{ Изменение свойств вулканизатов после воздействия морской воды $\left(23^{\circ} \mathrm{C} \times 30\right.$ сут $)$} \\
\hline$\Delta f_{\mathrm{p}}, \%$ & $-2,8$ & $-2,3$ & $-2,1$ & $-1,9$ & $-1,2$ \\
\hline$\Delta \varepsilon_{\mathrm{p}}, \%$ & $-5,3$ & $-4,9$ & $-4,3$ & $-3,8$ & $-3,1$ \\
\hline$\Delta m, \%$ & $+0,51$ & $+0,47$ & $+0,41$ & $+0,38$ & $+0,29$ \\
\hline \multicolumn{6}{|c|}{ Динамические свойства вулканизатов } \\
\hline $\operatorname{tg} \delta$ & 0,29 & 0,37 & 0,59 & 0,81 & 0,83 \\
\hline$E \cdot 10^{-8}$, Па & 1,52 & 1,27 & 1,38 & 1,45 & 1,83 \\
\hline
\end{tabular}

Примечание: $M_{\mathrm{H}}$ - максимальный крутящий момент; $M_{\mathrm{L}}-$ минимальный крутящий момент; $t_{\mathrm{s}}-$ время начала вулканизации; $t_{90}$ - оптимальное время вулканизации; $f_{100}$ - условное напряжение при $100 \%$-ном растяжении; $f_{\mathrm{p}}-$ условная прочность при растяжении; $\varepsilon_{\mathrm{p}}$ - относительное удлинение при разрыве; $H$ - твердость; $B$ - сопротивление раздиру; $\Delta f_{\mathrm{p}}, \Delta \varepsilon_{\mathrm{p}}$ и $\Delta m$ - относительное изменение условной прочности при растяжении, относительного удлинения при разрыве и массы; $\operatorname{tg} \delta$ - тангенс угла механических потерь; $E$ - модуль упругости

и гуанид Ф. В четвертом и пятом вариантах дополнительно в резиновую смесь вводились полиизобутилен П-200 и сэвилен 11808-340 соответственно. Исследованные варианты резиновой смеси, их вулканизационные характеристики, физико-механические и динамические свойства вулканизатов приведены в таблице. 
Как видно, введение ТПНБ, входящего в состав МД, во втором варианте резиновой смеси приводит к уменьшению максимального, минимального крутящих моментов и повышению времен начала и оптимума вулканизации. Частичная замена СКМС-30АРК на каучуки СКН-4065, СКИ-3, БК-1675, дополнительное введение полиизобутилена П-200 и сэвилена 11808-340 в третьем - пятом вариантах незначительно влияют на максимальный и минимальный крутящие моменты резиновой смеси по сравнению с первым и вторым ее вариантами. При этом наблюдается достаточно большое возрастание времен начала и оптимума вулканизации, что способствует улучшению перерабатываемости резиновой смеси методами шприцевания и каландрования - технологических операций изготовления заготовок резиновой смеси для вулканизации с последующим получением готовых резиновых изделий.

Полученные вулканизаты обладают различными физико-механическими свойствами. Так, при переходе от вулканизата первого варианта к вулканизату второго варианта происходит уменьшение физико-механических свойств за счет наличия ТПНБ, не содержащего двойные связи, которые участвуют в образовании сшитой структуры резины. Для вулканизатов третьего - пятого вариантов наблюдается возрастание физико-механических свойств за счет введения в вулканизующую систему «сера $+2,2$ '-дибензтиазолдисульфид» N-циклогексил-2бензотиазолсульфенамида и гуанида $\Phi$, которые увеличивают эффективность этой системы и степень сшивания каучуков [15].

Из результатов исследования физико-механических свойств вулканизатов после выдержки в морской воде следует, что вулканизат пятого варианта характеризуется наименьшими изменениями условной прочности при растяжении, относительного удлинения при разрыве и изменением массы после выдержки в морской воде по сравнению с вулканизатами первого - четвертого вариантов. Следовательно, пятый вариант резиновой смеси может быть рекомендован для изготовления изделий, эксплуатируемых в условиях воздействия морской воды.

Исследования динамических свойств вулканизатов показывают, что для второго варианта по сравнению с первым наблюдается возрастание тангенса угла механических потерь, приводящее к улучшению динамических свойств резины [16], что связано с содержанием ТПНБ во втором варианте резиновой смеси. Наблюдаемое снижение модуля упругости для вулканизата второго варианта коррелирует с отмеченным выше снижением для него прочностных свойств. Значение тангенса угла механических потерь для второго варианта резины является недостаточным и поэтому в третьем и четвертом вариантах резиновой смеси была проведена частичная замена каучука СКМС-30АРК на каучуки СКН-4065, СКИ-3 и дополнительное введение полиизобутилена П-200. Как видно, вулканизаты третьего и четвертого вариантов по сравнению с вулканизатом второго варианта характеризуются большими значениями тангенса угла механических потерь и модуля упругости. Для дальнейшего увеличения динамических свойств резины исследовался пятый вариант, в котором взамен СКИ-3 и полиизобутилена П-200 использовались бутилкаучук БК-1675 и сэвилен 11808-340. Из данных таблицы следует, что вулканизат пятого варианта резиновой смеси обладает наибольшим значением тангенса угла механических потерь и этот вариант резиновой смеси может быть рекомендован для изготовления изделий с повышенными виброизолирующими свойствами. 


\section{Заключение}

В данной работе изучено влияние каучуков и ингредиентов для резины, изделия из которой контактируют с морской водой, на ее динамические свойства. Исследованы вулканизационные характеристики резиновой смеси, физико-механические свойства и стойкость к воздействию морской воды резины на основе каучуков общего и специального назначения. Рассмотрена возможность повышения динамических свойств резины за счет введения в ее состав ТПНБ, полиизобутилена П-200, бутилкаучука БК-1675, сэвилена 11808-340. Показано, что резина с серной вулканизующей системой (сера, 2,2'-дибензтиазолдисульфид и гуанид Ф), включающая комбинацию каучуков СКМС-30АРК, СКН-4065 и БК-1675, 20,0 мас. ч. ТПНБ и 5,0 мас. ч. сэвилена 11808-340, обладает повышенными динамическими показателями, характеризуется улучшенными физико-механическими свойствами и наименьшими их изменениями после выдержки в морской воде.

\section{Благодарности / Acknowledgments}

Работа выполнена при реализации гранта № 5-20 Фонда развития науки ФГБОУ ВО «Чувашский государственный университет им. И.Н. Ульянова».

The work was carried out with the implementation of the grant No. 5-20 of the Science Development Fund of the FGBOU VO Chuvash State University named after I. N. Ulyanov.

\section{Список литературы / References}

1. Ohm R.F., Vial T.M. A New Synthetic Rubber Norsorex ${ }^{\circledR}$ Polynorbornene. Journal of Elastomers and Plastics 1978. Vol. 10(2), P. 150-162.

2. Frenzel U., Nuyken O. Ruthenium-Based Metathesis Initiators: Development and Use in RingOpening Metathesis Polymerization. Journal of Polymer Science Part A: Polymer Chemistry 2002. Vol. 40(17), P. 2895-2916.

3. Mol J.C. Industrial applications of olefin metathesis. Journal of Molecular Catalysis A: Chemical 2004. Vol. 213, P. 39-45.

4. Yamazaki M. Industrialization and application development of cyclo-olefin polymer. Journal of Molecular Catalysis A: Chemical 2004. Vol. 213, P. 81-87.

5. Бермешев М. В., Грингольц М. Л., Лахтин В. Г., Финкельштейн Е.Ш. Синтез и метатезисная полимеризация 5,5-бис(триметилсилил)норборнена-2. Нефтехимия 2008. Т. 48(4), С. $300-$ 305. [Bermeshev M.V., Gringolts M.L., Lakhtin V.G., Finkel'shtein E. Sh. Synthesis and metathesis polymerization of 5,5-bis(trimethylsilyl) norbornene-2. Petroleum Chemistry 2008. Vol. 48(4), P. 300305. (In Russ.)].

6. Богданова Ю. Г., Должикова В. Д., Грингольц М. Л., Костина Ю. В., Тихонов Н. А., Алентьев А.Ю. Влияние триметилсилильных заместителей в мономерном звене на энергетические характеристики поверхностей полинорборненов, полученных метатезисной полимеризацией. Высокомолекулярные соединения. Серия А 2013. Т. 55(8), С. 1039-1047. [Bogdanova Yu.G., Dolzhikova V.D., Gringol'ts M.L., Kostina Yu.V., Tikhonov N.A., Alent'ev A. Yu. The effect of trimethylsilyl substituents in the monomer unit on the energy characteristics of surfaces of polynorbornenes obtained via metathesis polymerization. Polymer Science, Series A 2013. Vol. 55(8), P. 1039-1047. (In Russ.)]. 
7. Leimgruber S., Trimmel G. Olefin metathesis meets rubber chemistry and technology. Monatshefte Für Chemie - Chemical Monthly 2015. Vol. 146(7), P. 1081-1097.

8. Cheng C.C., Chang C.S., Hsu Y.L., Lee T.Y., Chang L.C., Liu S.H., Wu Y.T. RutheniumCatalyzed Cascade Reactions of Diynes with Norbornadiene - Synthesis of Norbornene Derivatives. European Journal of Organic Chemistry 2010. No. 4, P. 672-679.

9. Суслов Д. С., Быков М. В., Кравченко О. В. Аддитивная полимеризация норборнена с катализаторами на основе соединений переходных металлов: 2008-2018. Высокомолекулярные соединения. Серия С 2019. T. 61(1), C. 122-151. [Suslov D. S., Bykov M. V., Kravchenko O. V. Norbornene addition polymerization with catalysts based on transition metal compounds: 2008-2018. Polymer Science. Series C2019. Vol. 61(1), P. 122-151. (In Russ.)].

10. Патент 2690807 РФ. Михайлов Ю. М., Резников М.С., Мингазов А.Ш., Ушмарин Н. Ф., Сандалов С.И. Композиционная резиновая смесь для акустических покрытий. Опубл. 05.06.2019. [Patent 2690807 RU. Mikhajlov Yu. M., Reznikov M. S., Mingazov A. S., Ushmarin N.F., Sandalov S. I. Composite rubber mixture for acoustic coatings. Publ. Date 05.06.2019 (In Russ.)].

11. Патент 2675557 РФ. Михайлов Ю. М., Мингазов А.Ш., Резников М.С., Ушмарин Н.Ф., Чумаков К.И., Старухин Л.П. Резиновая смесь для изготовления шумопоглощающих покрытий. Опубл. 19.12.2018. [Patent 2675557 RU. Mikhajlov Yu. M., Mingazov A. S., Reznikov M.S., Ushmarin N.F., Chumakov K. I., Starukhin L.P. Rubber mixture for manufacture of noise absorbing coatings. Publ. Date 19.12.2018 (In Russ.)].

12. Чайкун А.М., Алифанов Е.В., Наумов И.С. Резины на основе бутилкаучука (обзор). Новости материаловедения. Наука и техника 2016. № 6(24), С. 49-59. [Chaikun A.M., Alifanov E. V., Naumov I. S. Rubbers based on butyl rubber (review). Materials science news. Science and technology 2016. No. 6 (24), P. 49-59 (In Russ.)].

13. Патент 2339658 РФ. Данлэп Пол Н., Саут Бобби Э. Резиновая композиция и демпфер вибраций с использованием резиновой композиции. Опубл. 27.11.2008. [Patent 2339658 RU. Danlehp Pol N., Saut Bobbi Eh. Rubber composition and vibration damper using rubber composition. Publ. Date 27.11.2008 (In Russ.)].

14. Черкасов В. Д., Волоцкой А.Н., Юркин Ю. В., Авдонин В. В. Влияние полярности наполнителей на динамические свойства вибропоглощающих полимерных композиционных материалов на основе этиленвинилацетата. Региональная архитектура и строительство 2020. № 1(42), C. 52-62. [Cherkasov V. D., Volotskoy A. N., Yurkin Yu.V., Avdonin V. V. Influence of the polarity of fillers on the dynamic properties of vibration-absorbing polymer composite materials based on ethylene vinyl acetate. Regional architecture and construction 2020. No. 1 (42). P. 52-62 (In Russ.)].

15. Большой справочник резинщика / Под ред. Резниченко С. В., Морозова Ю. Л. Ч. 1. Каучуки и ингредиенты. М.: Техинформ МАИ, 2012. 744 c. [Great reference book of the rubber worker. Ed. Reznichenko S. V., Morozov Yu.L. Part 1. Rubbers and ingredients. Moscow: Tekhinform MAI, 2012. 744 p. (InRuss.)].

16. Платонов М.М., Шульдешов Е.М., Нестерова Т.А., Сагомонова В.А. Акустические полимерные материалы нового поколения (обзор). Труды ВИАМ 2016. № 4(40), С. 76-84. [Platonov M. M., Shuldeshov E. M., Nesterova T. A., Sagomonova V. A. Acoustic polymeric materials of a new generation (review). VIAM Proceedings 2016. No. 4 (40), P. $76-84$ (In Russ.)]. 